\title{
INFLUÊNCIA DA LUZ E DA TEMPERATURA NA GERMINAÇÃO DE UREDOSPOROS DE PUCCINIA PSIDII ( $\left.{ }^{1}\right)$
}

\author{
SOLANGE MONTEIRO DE TOLEDO PIZA $\left({ }^{2}\right)$ \\ e IVAN JOSÉ ANTUNES RIBEIRO $\left({ }^{3}\right)$
}

\begin{abstract}
RESUMO
Com a objetivo de determinar as melhores condições para germinação de uredosporos de Puccinia psidii Winter, testaram-se duas temperaturas e cinco fotoperiodos. Determinou-se que $18^{\circ} \mathrm{C}$ e oito horas de escuro são as condiçōes que propiciam a melhor germinação dos uredosporos.
\end{abstract}

Termos de indexaçāo : Puccinia psidii Winter; luz; temperatura; geminaçăo.

O fungo Puccinia psidii Winter é sério problema para grande número de mirtáceas de valor econômico, como, por exemplo, a goiabeira e o eucalipto.

O clima exerce influência marcante sobre o desenvolvimento de doenças, pois pode atuar sobre o patógeno, sobre o hospedeiro e sobre a interação patógeno-hospedeiro. $\mathrm{O}$ conhecimento das exigências climáticas dos fitopató-

(1) Recebido para publicação em 10 de setembro e aceito em 9 de novembro de 1987.

(2) Engenheira-Agrônoma estagiária, Seçăo de Microbiologia Fitotécnica, Instituto Agronómico (IAC), Caixa Postal 28, 13001 Campinas (SP). Com bolsa de aperfeiçoamento da FAPESP.

(3) Seçâo de Microbiologia Fitotécnica, IAC. 
genos é de grande importância para o entendimento da evolução da doença no campo, e para se prever, com certa precisão, a ocorrência de epifitias em determinadas condições climáticas e agrícolas de uma região (KRÜGNER, 1978).

Entre os fatores climáticos mais estudados, encontram-se a temperatura e o fotoperíodo.

FERREIRA (1981) determinou que a temperatura de $15^{\circ} \mathrm{C}$ é a melhor para a germinação de uredosporos de $P$. psidii. CASTRO (1983), trabalhando com - sistema eucalipto-Puccinia psidii, obteve a maior e a menor intensidade de infecção, respectivamente, nas temperaturas de $24,5 \pm 1,2^{\circ} \mathrm{C}$ e $17,0 \pm 0,6^{\circ} \mathrm{C}$. RUIZ et al. (1987), trabalhando com as temperaturas de $10,15,20,25$ e $30^{\circ} \mathrm{C}$, durante o período de câmara úmida, chegaram à conclusão que o máximo de infecção ocorreu às temperaturas de 20 e $25^{\circ} \mathrm{C}$. No entanto, COUTINHO \& FIGUEIREDO (1984), inoculando jambeiro com $P$. psidii, não obtiveram nenhum sintoma quando as temperaturas máximas foram superiores a $25^{\circ} \mathrm{C}$. Os autores também citaram as temperaturas de 22 a $24,5^{\circ} \mathrm{C}$ como as mais favoráveis à produção de uredosporos.

Em relação ao efeito da luz, CASTRO (1983) observou que, mantendo-se mudas de eucalipto por doze horas no escuro após a inoculação, obtinha-se maior infecção do que mantendo-as no claro. RUIZ et al. (1987) inocularam mudas de eucalipto e submeteram-nas a vários fotoperíodos, concluindo que a infecçāo foi inversamente proporcional ao tempo de exposição à luz.

Contudo, é nas fases de germinação e penetração que o clima pode atuar mais diretamente sobre o patógeno, pois este ainda não ganhou o interior do hospedeiro e está mais exposto à ação do ambiente (KRÜGNER, 1978).

Assim, este trabalho visou determinar as condições de luz e temperatura que mais favorecem a germinação de $P$. psidii.

\section{Material e métodos}

A germinação foi feita sobre tiras de papel celofane de aproximadamente $2,5 \times 7,5 \mathrm{~mm}$, mantidas em câmara úmida. Uma suspensão de uredosporos em água estéril, na concentração de $2 \times 10^{4}$ esporos por mililitro, foi pulverizada sobre o papel, com auxilio de um pulverizador De Vilbiss. Testaram-se as temperaturas de 18 e $22^{\circ} \mathrm{C}$ em cinco fotoperíodos (delineamento fatorial $2 \times 5$ ), totalizando dez tratamentos com três repetições cada um, sendo cada repetição constituída de uma faixa de papel celofane em câmara úmida.

Os fotoperíodos foram os seguintes: luz contínua; 4 horas de escuro/20 horas de luz; 8 horas de escuro/16 horas de luz; 16 horas de escuro/8 horas de luz e 24 horas de escuro. Nos tratamentos em que houve alternância de luz e escuro, o período no escuro sempre precedeu o na luz. Após 24 horas, efetua- 
ram-se as contagens, ao acaso, de cem esporos em cada repetição, determinando-se assim as porcentagens de germinação.

Para efeito de análise estatística, os dados foram transformados em arco seno $\sqrt{\% / 100}$ e analisados segundo o delineamento experimental fatorial inteiramente ao acaso.

\section{Resultados, discussão e conclusões}

No quadro 1 , nota-se que a germinação dos uredosporos foi sempre maior a $18^{\circ} \mathrm{C}$, independente do fotoperíodo, exceto em luz contínua, quando entáo as porcentagens de germinaçāo foram estatisticamente iguais para as duas temperaturas. A maior resposta ao fotoperíodo, indicada pela maior porcentagem de germinação, ocorreu quando os esporos foram colocados a $18^{\circ} \mathrm{C}$ e fotoperíodos de 8,16 e 24 horas no escuro. A única diferença entre os fotoperíodos, a $22^{\circ} \mathrm{C}$, foi entre os tratamentos claro contínuo e 24 horas de escuro.

Esses resultados confirmam os obtidos por FERREIRA (1981), que observou que temperaturas ao redor de $15^{\circ} \mathrm{C}$ favorecem a germinação dos uredosporos. Por outro lado, pode-se notar que as temperaturas ideais para a germinaçāo não são as mesmas para a infecção, pois RUIZ et al. (1987) verificaram que temperaturas entre 20 e $25^{\circ} \mathrm{C}$ durante a câmara úmida são mais favoráveis à infecção, enquanto CASTRO (1983) e COUTINHO \& FIGUEIREDO (1984) observaram que temperaturas ao redor de $24^{\circ} \mathrm{C}$ são as mais adequadas para a produção de soros urediniais.

QUADRO 1. Efeito de cinco fotoperíodos e duas temperaturas sobre a porcentagem de germinação dos uredosporos de Puccinia psidii (média de três repetiçōes)

\begin{tabular}{|c|c|c|c|c|c|}
\hline \multirow{2}{*}{$\begin{array}{l}\text { Horas no } \\
\text { escuro }\end{array}$} & \multicolumn{2}{|c|}{$18^{\circ} \mathrm{C}$} & \multicolumn{2}{|c|}{$22^{\circ} \mathrm{C}$} & \multirow{2}{*}{$\frac{\text { Média }}{\substack{\text { Germinação } \\
(\%)}}$} \\
\hline & $\begin{array}{c}\text { Germinação } \\
(\%)\end{array}$ & $\frac{\text { Arc sen }}{\sqrt{\% / 100}}$ & $\begin{array}{c}\text { Germinação } \\
(\%)\end{array}$ & $\frac{\text { Arc sen }}{\sqrt{\% / 100}}$ & \\
\hline 0 & 2,3 & $8,47 \mathrm{~A} \mathrm{a}$ & 1,0 & $5,74 \mathrm{~A} a$ & 1,6 \\
\hline 4 & 12,3 & $20,54 \mathrm{Ab}$ & 3,3 & $10,40 \mathrm{~B} \mathrm{ab}$ & 7,8 \\
\hline 8 & 22,0 & $27,96 \mathrm{~A} \mathrm{C}$ & 4,3 & $11,90 \mathrm{~B} \mathrm{ab}$ & 13,1 \\
\hline 16 & 23,0 & $28,65 \mathrm{~A} \mathrm{C}$ & 4,3 & $11,74 \mathrm{~B} a b$ & 13,6 \\
\hline 24 & 28,3 & $32,16 \mathrm{AC}$ & 6,0 & $13,64 \mathrm{~B} \mathrm{~b}$ & 17,1 \\
\hline Média & 17,6 & 23,56 & 3,8 & 10,68 & \\
\hline
\end{tabular}

C.V.: $13,7 \%$.

Obs: Letras maiúsculas diferentes na mesma linha e letras minúsculas diferentes na mesma coluna indicam diferenças significativas pelo teste de Tukey ao nivel de 1 e $5 \%$ respectivamente $\left(\mathrm{DMS}_{1 \%}=8,30\right.$ e $\left.\mathrm{DMS}_{5 \%}=6,82\right)$. 
Em relação ao efeito da luz, CASTRO (1983) e RUIZ et al. (1987) obtiveram as maiores infecções quando as plantas permaneceram no escuro após a inoculação, o que confirma os dados do presente trabalho, de que a melhor germinação ocorre em condições de escuridāo.

Pelo exposto, pode-se concluir que a maior porcentagem de germinação dos uredosporos de $P$. psidii ocorre em condiçōes de temperaturas amenas $\left(18^{\circ} \mathrm{C}\right)$ associadas à ausência de luz por cerca de oito horas, o que acontece facilmente durante a noite em várias épocas do ano. Além disso, deve-se frisar que são necessários mais estudos sobre a influência do clima no sistema goiabeira-Puccinia psidii, uma vez que as condiçōes determinadas como as melhores para a germinação do fungo não o são, provavelmente, para as demais fases do ciclo.

\section{SUMMARY}

\section{INFLUENCE OF LIGHT AND TEMPERATURE ON UREDOSPORES GERMINATION OF PUCCINIA PSIDII WINTER}

The objective of this experiment was to study the influence of light and temperature on uredospore germination of Puccinia psidii Winter. Two temperatures $\left(18^{\circ} \mathrm{C}\right.$ and $\left.22^{\circ} \mathrm{C}\right)$ and five patterns of illumination $(0,4,8,16$, and 24 hours of darkness) were tested. The results showed that the temperature of $18^{\circ} \mathrm{C}$ and 8 hours of darkness were the most favorable conditions for the uredospores germination.

Index terms : Puccinia psidii Winter, temperature; light, germination.

\section{REFERÊNCIAS BIBLIOGRÁFICAS}

CASTRO, H. Padronização da metodologia de inoculação e avaliação da resistência de Eucalyptus spp. à ferrugem causada por Puccinia psidii Winter. Piracicaba, ESALQ, USP, 1983. 105p. Tese (Doutoramento)

COUTINHO, L.N. \& FIGUEIREDO, M.B. Efeito da temperatura na produção de uredosporos e teliosporos de Puccinia psidii. Fitopatologia Brasileira, Brasíia, 9(2):326, 1984.

FERREIRA, F.A. Ferrugem do eucalipto - ocorrências, temperatura para germinação de uredosporos, produção de teliosporos, hospedeiro alternativo e resistência. Fitopatologia Brasileira, Brasília, 6(3):603-604, 1981.

KRÜGNER, T.L. Ação do ambiente sobre doenças de plantas. In: GALLI, F., coord. Manual de Fitopatologia. São Paulo, Ceres, 1978. v1, p.215-225.

RUIZ, R.A.R.; ALFENAS, A.C. \& DO VALE, F.X.R. Influência da luz e do binômio temperatura-tempo de água líquida para infecção de Puccinia psidii em Eucalyptus grandis. Fitopatologia Brasileira, Brasilia, 12(2):137, 1987. 